DOI: 10.17707/AgricultForest.61.1.31

\author{
Noureddin DRIOUECH, \\ Luigi SISTO, Onofrio LORUSSO and Maurizio RAELI ${ }^{1}$
}

\title{
ALUMNI NETWORK AND PEER LEARNING: EXPERIENCE OF MEDITERRANEAN AGRONOMIC INSTITUTE OF BARI
}

\begin{abstract}
SUMMARY
A number of higher education and training institutions promote teaching methods that enable 'active' learning by offering trainees the opportunity to formulate questions, discuss problems, explain their points of view and use a "collaborative" approach based on teamwork for problem and project management. Peer Learning is a form of collaborative instruction that enhances the student/student interaction and leads to definitely positive learning results. This work deals with a spontaneous Peer Learning process occurring within the context of an eLearning follow-up course on "Invasive Fruit Tree Pest Surveillance in The Mediterranean Region". This course lasting 10 weeks was addressed to 40 former trainees of the MAIB institutional Master of Science program in "Integrated Pest Management of Mediterranean Crops", members of the Alumni Network of the Institute. In fact, within the Discussion Fora significant students contributions were posted introducing additional information and knowledge to the course contents (131 out of 907). Furthermore, the occurrence of complete cycles of different types of post "Episodes" called "dialogic cycle" in different modules of the course has shown the actual occurrence of Peer Learning. This confirms the actual trend to changes in the production/development and in the consumption/use of information and knowledge, so that the role of the student is enhanced through a new form of collaboration between peers, in which the student is a "producer of knowledge".
\end{abstract}

Keywords: Alumni, Peer learning, Communities of Practice, Agricultural education, Mediterranean and Balkan areas

\section{INTRODUCTION}

The "collaborative-constructivist" method applied in the specific context of Alumni, hence adult participants, created favorable conditions for creating a community of practice on subjects of common interest. Moreover, the criteria for selection of participants helped identify (or rather target) the profile of

\footnotetext{
1 Noureddin DRIOUECH, (corresponding author: driouech@iamb.it), coordinator of Ciheam-Alumni Network (FTN), Luigi SISTO, Onofrio LORUSSO, ICT department, Maurizio RAELI, Deputy director of CIHEAM/Mediterranean Agronomic Institute, BariItaly
} 
experienced professionals particularly interested in the subjects proposed in the course.

In a context of Alumni networking, follow-up studies are commonly used by academic and research institutions to evaluate and assess the effectiveness of their educational and academic programs. The results of such studies can be used to avoid mistakes and improve performance in the future (Erickson, 1947). Those studies often seek to measure the relationship between the training the students received and the expertise needed for their occupational placement (Randavay, 1990). Moreover, Graham (2001) reported that If Agricultural industries are to survive; the agriculture curriculum must be dynamic and able to adjust to new situations and environment that help to improve on-the-job effectiveness of future graduates.

In 2010, in order to accomplish its education/training mission through distance learning program, Ciheam-MAI of Bari has set up Alumni Network. The Network is aimed also to build a Mediterranean Community of Practice through Information sharing, knowledge generation, exchange and dissemination.

In the case of CIHEAM MAI of Bari education and training programmes, the Alumni network represents the optimal environment for the realization of the peer learning process and phenomena. Peer learning can be defined as the acquisition of knowledge and skill through active helping and supporting among status equals or matched companions. It involves people from similar social groupings who are not professional teachers helping each other to learn and learning themselves by so doing (Topping, 2005).

The process came up within Discussion Fora of the course delivered on MAIB eLearning platform where significant contributions were posted that introduced additional information to the course contents (131 out of 907). Therefore the analysis of innovative posts ("Episode") was carried out using a customized method taken from the literature on the subject (Lambropoulos et al., 2012). Therefore, the present research work attempted mainly to: (i) review the conceptual developments in forms of peer learning and community of practice under Alumni network environment (ii): provide insights about the extents of Alumni Network and Peer Learning under Ciheam MAI of Bari experience follow-up online course and (iii) highlight the effectiveness of "collaborative" method applied in eLearning courses in combination of Alumni Network in facilitating peer learning process.

\section{MATERIAL AND METHODS}

The present review paper is based on author's literature review of the conceptual frame of Peer learning (PL), Cooperative Learning, Communities of Practice (CoPs) and their practical implications under Ciheam-MAIB Follow-up distance learning program (DLP) and Alumni networking. In addition, Criteria of participants selection was explained, Forum activities and Analysis of posts were measured and performed. 
Furthermore, the DLP has been included in an institutional (CIHEAM) action which main goal was to update the Alumni Network member's knowledge on "Sustainable Management of Natural Resources" through distance learning courses to follow up and facilitate access to an interactive community finalized to a continuous exchange among alumni, visiting lecturers, staff, researchers and consultants. The title of the course was: "Invasive Fruit Tree Pests Surveillance In The Mediterranean Region" and it has been aimed to improve the past IPM (Integrated Pest Management) Master of Science students knowledge for developing an harmonized pest alert system in the Mediterranean region and preventing and/or containing the most alarming invasive/emerging fruit tree pests for a beneficial socio-economic impact in food safety and improving Mediterranean fruit industry competitiveness. This follow-up course has been designed for about 40 professionals, engineers and technical personal, working in governmental and non-governmental institutions dealing with integrated pest management. The Mediterranean Agronomic Institute of Bari (MAIB) former students of Master Course "Integrated Pest Management" (Academic year 20002010) and members of the Former Trainees Network (FTN) were the main target.

The DLP has been structured into two phases: the first one is the "Preliminary period" of 3 weeks (23 September -13 October 2013) which allowed creating the "Community of learning". The second one is the "Peer Learning period" (14 October- 30 November 2013) which extended on 5 thematic modules.

\section{RESULTS AND DISCUSSION}

Communities of Practice building and Criteria for selection of participants

A-Follow-up study description:

The tool used to conducted the follow-up survey is a self-administered questionnaire. It was designed and developed in August-September 2010 and was made available through the surveymonkey website, in English (https://www.surveymonkey.com/s/XJQPK95) and French (https://www.survey monkey.com/s/68XHYN6) languages. More than 1300 former students/trainees, who attended Educational / Training programs at MAI of Bari between the years 1998 and 2010, were invited via email, phone or fax to follow a link which allowed them to complete the questionnaire online. Participation was entirely volunteer and responses were analyzed only in aggregate.

The questionnaire used a combination of one and/or multiple choice and open-ended questions, allowing for free text input. It was developed into 2 main sections A: FTN data base updating and B: FTN Follow-up. The two sections are articulated in 6 parts: (1) General information and demographic data; (2) Career progress and further development; (3) Recognition of research excellence; (4) Commercial spin-offs; (5) Scientific outputs and (6) Overall evaluation.

$B$-Online course dissemination strategy:

Based on the follow up research findings (e.g. students profiles, IPM academic years.etc), the dissemination and course promotion was targeted. The 
tool used was a direct emailing through Comm100 Email marketing system (www.comm100.com).

In addition, various institutional communication channels were used, such as: Alumni Network (FTN) of CIHEAM - IAMB: http://hosted.comm100.com/HelpDesk/Main/Main.aspx?siteId=53331

Furthermore, Alumni community social networks (Facebook, LinkedIn and Twitter), were used to disseminate the course announcement.

For the promotion/dissemination of the on-line course among the Alumni Network members through direct e-mailing, there were two communications as described in table 1 . Total number of respondents and selected students was about 50.

Table 1. Statistics regarding communication for the course dissemination

\begin{tabular}{|l|l|c|c|c|c|c|c|}
\hline Communication & $\begin{array}{l}\text { Sending } \\
\text { date }\end{array}$ & $\begin{array}{l}\text { Recipient } \\
\text { number }\end{array}$ & $\begin{array}{l}\text { Bounced } \\
\text { e-mails }\end{array}$ & $\begin{array}{l}\text { Delivered } \\
\text { e-mails }\end{array}$ & $\begin{array}{l}\text { Opened } \\
\text { e-mails }\end{array}$ & $\begin{array}{l}\text { licked } \\
\text { course } \\
\text { program } \\
\text { Link }\end{array}$ & $\begin{array}{l}\text { Total } \\
\text { number of } \\
\text { respondents }\end{array}$ \\
\hline First & $09 / 08 / 2013$ & 167 & $\begin{array}{c}50 \\
(31.06 \%)\end{array}$ & $\begin{array}{c}111 \\
(68.94 \%)\end{array}$ & $\begin{array}{c}111 \\
(68.94 \%)\end{array}$ & $\begin{array}{c}33 \\
(29.73 \%)\end{array}$ & \\
\hline $\begin{array}{l}\text { Second } \\
\text { (Reminder) }\end{array}$ & $17 / 07 / 2013$ & 3683 & $\begin{array}{c}166 \\
(4.51 \%)\end{array}$ & $\begin{array}{c}3517 \\
(95.49 \%)\end{array}$ & $\begin{array}{c}746 \\
(21.21 \%)\end{array}$ & $\begin{array}{c}746 \\
(21.21 \%)\end{array}$ & 50 \\
\hline
\end{tabular}

-All percentages in brackets refer to recipients' number

Alumni Network, Information Technology and Peer Learning

In recent years, information technology has begun to permeate peer learning in various ways. First, peer learning at a distance in online communities such as Alumni Network has been extensively explored. Graham (2002) reviewed the research into creating effective cooperative learning in face-to-face and virtual environments for distance education, with particular emphasis upon creating the groups, structuring learning activities, and facilitating group interactions. Davies (2000) researched computerised peer assessment in university. McLuckie and Topping (2004) defined and devised means of assessing the transferable skills needed for effective peer learning in online contexts, identifying the advantages and disadvantages of the online context.

Second, software has been developed intended to help manage peer learning, providing a management information system for the coordinator or facilitator of a program (e.g. I-Help; Bull \& McCalla, 2002). This is particularly necessary in cross-age or cross-institution peer learning in complex distributed environments.

Third, formative computer-aided assessment has been linked to tutoring systems, so that both helpers and helped receive regular, frequent, and timely feedback on the effectiveness of their learning together (Topping, 1999).

Finally, systems have been devised for tutoring by artificial intelligences (Merrill, Reiser, Ranney, \& Trafton, 1992), but these have some way to go before approaching the skill levels and adaptability of human tutors. 
The need for definition: Types of Peer Learning, Implementation, and Effects

The first question that emerges when we start discussing Peer learning in a global context is one of definition. The longest established and most intensively researched forms of peer learning are Peer tutoring and cooperative Learning. Both have been researched more in schools than in other contexts.

Box 1: Peer tutoring (PT) is characterised by specific role taking as tutor or tutee, with high focus on curriculum content and usually also on clear procedures for interaction, in which participants receive generic and/or specific training. Some peer tutoring methods scaffold the interaction with structured materials, while others prescribe structured interactive behaviours that can be effectively applied to any materials of interest.

Confusion between "tutoring" and "mentoring" is evident in the literature. Mentoring can be defined as an encouraging and supportive one to one relationship with a more experienced worker (who is not a line manager) in a joint area of interest. It is characterised by positive role modelling, promotion of raised aspirations, positive reinforcement, open ended counselling, and joint problem solving. It is often cross age, always fixed role, quite often cross institution, and often targeted to disadvantaged groups.

Box 2: Cooperative learning (CL) is more than "working together" - it has been described as "structuring positive interdependence" (Slavin, 1990) in pursuit of a specific shared goal or output. This is likely to involve the specification of goals, tasks, resources, roles, and rewards by the teacher, who facilitates or more firmly guides the interactive process. Typically operated in small groups of about six heterogeneous learners, $C L$ often requires previous training to ensure equal participation and simultaneous interaction, synergy, and added value. Having all group members work with the same information might heighten cognitive conflict but risks intragroup comparison and "competence threat". Higher effect sizes tend to be associated with approaches which combine group goals and individual accountability. At its worst CL can result in "the blind leading the blind" or "pooling ignorance", or one person doing all the work - hence the need for structure.

\section{What Peer Learning is NOT!}

There are many ways we learn. Not all of them involve peers. But if you get creative, just about any solo learning experience can become peer learning. All you have to do is invite in at least one other person. For example, self pace learning modules that rely solely on sequenced content is not peer learning. UNLESS you do it with someone else. Listening to a recorded webinar is not peer learning, but the fact that someone else took the time to make previous interactions available to others is an indication of relationship and accountability to others - to peers - for learning. Teams are dedicated to completing a shared task in a specific time. But along the way, they can learn together. 
The bottom line? We each know a lot. When we make that available to each other through both interactions and the artifacts of our interactions (summaries, blog posts, recordings) we all learn. That's peer learning!

Box. 3: Communities of Practice (CoPs) Communities of practice (CoPs) are groups of people who share a concern or passion for something that they do, and who interact regularly to learn how to do it better (Wenger, 2007). Communities of Practice (CoPs) are one form of peer learning. Not all peer learning happens in CoPs, but the framework that sits beneath CoPs can be a useful tool to plan, design and evaluate peer learning.

CoPs sit on a "three legged stool" of Domain, Community and Practice. What the community cares about, who is in the community and how they relate to each other and how they learn together and take the learning out into their lives, work and play.

Communities of practice are often identified as key ways for people to do professional development. It is through the process of sharing information and experiences with the group that the members learn from each other, and have an opportunity to develop themselves personally and professionally (Lave \& Wenger 1991). CoPs can exist online, such as within discussion boards and newsgroups, or in real life, such as in a lunchroom at work, in a field setting, on a factory floor, or elsewhere in the environment.

Organizations and Institutions often use CoPs to share knowledge thematically, across traditional silos and team work (e.g FAO Global Forum on Food Security and Nutrition, e-Agriculture, and the Mitigation of Climate Change in Agriculture (Loumbeva et al., 2009); AgoraMedspring for Policy, Research and Innovation, Feeding Knowledge programme for Food Security (Raeli, Personal communication, 2014). While teams focus on work outputs, CoPs focus on learning. CoPs also can exist across and outside of organizations.

Box 4 : Ciheam MAI of Bari Distance Learning methodology In order to ensure the best possible outreach, the on line course sessions have been delivered through MAIB eLearning platform (Claroline). Through a multiple instructional setting, the goal was to achieve the learning objectives by means of learning technologies that match individual learning styles and based on "collaborative" learning approach that aims at the development of just in time skills of adult learners. At the same time, in order to allow participants maximum flexibility of scheduling, the learning has been conducted in an asynchronous manner. The mean length of time required to each student was about 8 hours per week. MAIB model combines self learning with assessments, on line interaction and Forum discussions. The pedagogy adapted specifically to professionals in full time work could help train participants through various experiences: absorb : reading of teaching material (texts and Various media); do: execution of all exercises, consultation of recommended and suggested reading and sites (i.e.: Bibliography, Linkography and Glossary) and self evaluation test; interact: socialize and discuss on Forum space ; reflect : relate to one's own reality by the production of a short essay not exceeding 500 words and (at least 300 words) or an exercise. 
Case of IPM follow-up online course: findings. Measuring forum activities According to the interaction in online learning (Hopkinson, 2002), a good production of "social" messages is a "substrate" for a good production of "develop" or thematic messages. In the classical eLearning approach, "social" contributions usually convey "thematic" messages following parallel or even equidistant trends, Figure 1a. This process is justified by the fact that students need to build appropriate social relationships, even before participating actively in fora.

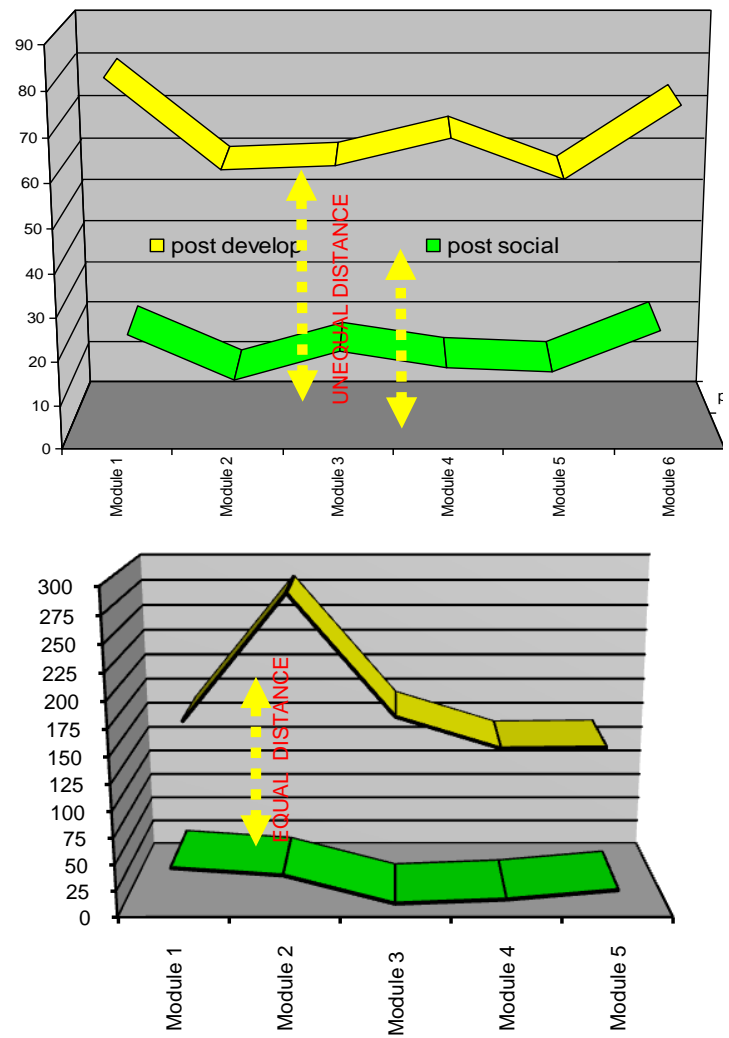

Fig. 1. - a: Classical trend of the social and develop posts (Source: authors' elaboration from MAIB ELearning Data); - $b$ : Peer learning trend of social and develop posts

In our specific case, considering the selection criterion (members of the Alumni Network) participants have previously gained a social experience (1 to 2 years) as they were involved in residential training programmes at MAIB campus (former trainees of IPM Master course). This has facilitated students' involvement in Peer learning activities in a context of community of practice (CoPs) Figure 1b.

Moreover, online participation, oriented to collaborative-constructivist activity (distance learning MAIB method), may be estimated. This estimate 
creates a relationship between written contributions or posts (reaction) and "seen" messages (action) through the whole period. This is important to establish whether and to what extent the forum tool has been effective to support learning. To come to a study closer to the real world, we report a statistical sample produced by a study group within a MAIB case study. The sample is made up of: "develop" posts (exchanges of messages strictly related to the themes under study) and "seen" posts appropriately refined from the number of incidental accesses estimated at around $30 \%$ (noise) Table 2.

Table. 2. Comparison of develop and seen posts

\begin{tabular}{|l|c|c|}
\hline \multirow{2}{*}{ Forum activities } & Group \\
\cline { 2 - 3 } & Post & Seen $(-30 \%)$ \\
\hline $\begin{array}{l}\text { Module 1: Control of the peach fruit fly, } \\
\text { Bactrocera zonata. }\end{array}$ & 120 & 700 \\
\hline $\begin{array}{l}\text { Module 2: Control and surveillance of the Red Palm Weevil } \\
\text { in the Mediterranean area }\end{array}$ & 251 & 1706 \\
\hline Module 3: Monitoring of Sharka disease of stone fruits & 131 & 1170 \\
\hline $\begin{array}{l}\text { Module 4: Surveillance of Citrus tristeza virus and its vector } \\
\text { Toxoptera citricidus }\end{array}$ & 107 & 918 \\
\hline $\begin{array}{l}\text { Module 5: Alert system for the control of Fire blight disease } \\
\text { of pome fruits }\end{array}$ & 117 & 1114 \\
\hline
\end{tabular}

For a theoretical estimate of "teaching induction" (Lorusso et al., 2011) we have taken into account the whole period (from module 1 to 5) and the relationship between the number of written messages or posts and "seen" posts so that $\mathrm{R}^{2}$ (the coefficient of determination) was calculated using linear regression (least squares method). It is observed that the members of the group under study have most benefitted $\left(R^{2}=0,9\right)$ from the exchange of thematic messages. This result (Figure 2) is compatible with the peer learning process attributable to environments of Alumni and thus to the "Communities of Practices (CoPs)".

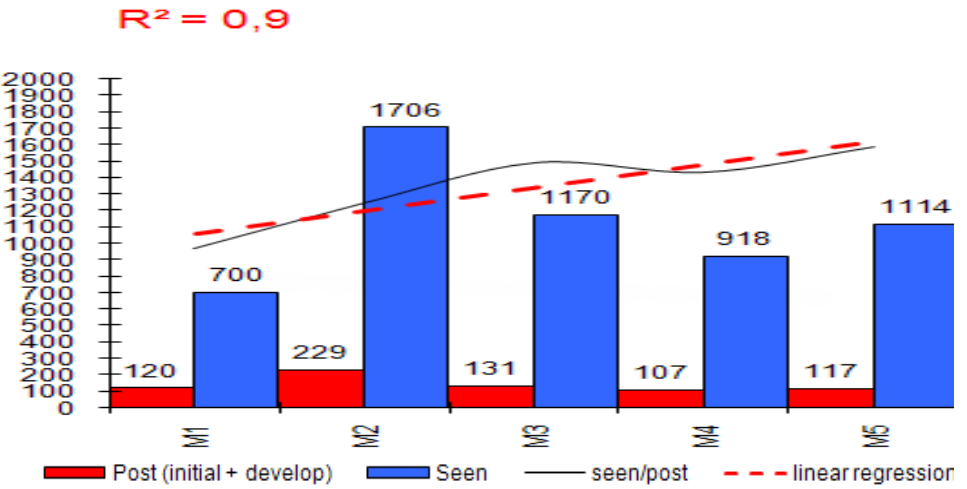

Fig. 2: Sample group: measure of participation in discussion fora 
Analysis of posts. If e-students have been instructed on how to get involved in "Collaborative Learning", this could be useful in the "coconstruction" of new knowledge. This activity, as already described, is mostly developed in discussion fora through different types of posts, classified according to Hopkinson (2002) as social, initial, help and develop. In particular "develop" posts, i.e. those useful to develop the subject under study, may be enriched with additional information and originate "value-added" contributions that can be defined "episode posts". Subsequently, the more active participants, who share the same objective-interest, are involved in a dialogue sequence of "episode posts" called "dialogic cycle", i.e. an open reasoning cycle.

In the course under study, the above "episode posts" were identified using a method found in the literature (Lambropoulos et al., 2012) "...it is proposed to measure its pedagogical value in real time with attributes described as follows: inform (suggestion), question (reflection), explain (elaboration), explore (elaboration), idea (co-construction), agree (judgment), evaluate (estimation) and others."

You find below the applied grid of analysis of "episode posts" that includes different types of interaction with the related description.

Table 3: Type of "episode posts" according to Lambropoulos et al., (2012)

\begin{tabular}{|l|l|}
\hline \multicolumn{1}{|c|}{$\begin{array}{c}\text { Types of } \\
\text { interaction }\end{array}$} & Description \\
\hline Inform & $\begin{array}{l}\text { Suggestion and innovative proposal with regard to the contents of } \\
\text { the module }\end{array}$ \\
\hline Question & Question arising from reflection \\
\hline Explain & Elaboration of text or explanatory depiction \\
\hline Explore & Exploring and searching related subjects \\
\hline Idea & Expressing concepts or additional elements \\
\hline Agree/disagree & Critical expression and negotiation \\
\hline Evaluate & Judgment and shared evaluation of new information and ideas \\
\hline
\end{tabular}

The above method has been applied to analyse the posts in the fora of all modules including recovery modules (Rec.), whose outcomes are shown in tab 4.

Table 4: Posts in the fora of all modules including recovery modules (Rec.)

\begin{tabular}{|l|c|c|c|c|c|c|c|}
\hline $\begin{array}{l}\text { Interaction } \\
\text { posts/Modules }\end{array}$ & Mod. 1 & Mod. 2 & Mod. 3 & Mod. 4 & Mod. 5 & Rec. 1 & Rec. 2 \\
\hline Inform & 7 & 5 & 1 & & 4 & & 10 \\
\hline Question & 8 & 2 & 2 & 3 & 2 & 1 & 2 \\
\hline Idea & 2 & 2 & 2 & 1 & & 2 & \\
\hline Explain & 13 & 4 & 4 & 3 & 1 & 1 & 1 \\
\hline Explore & 6 & 1 & 3 & 3 & 6 & 2 & 1 \\
\hline Agree/disagree & 4 & 1 & 3 & 1 & 3 & 3 & \\
\hline Evaluate & 3 & 2 & 2 & 1 & & 2 & 2 \\
\hline
\end{tabular}


The data in the above table reveal a significant production of "episode posts" in all modules of the course. This may be interpreted as a clear expression of Peer Learning, considering that there has been a well-balanced distribution of all types of interaction.

This distribution suggests that indeed there have been different reasoning cycles, or dialogic cycles that attest further the occurrence of Peer Learning process.

\section{CONCLUSIONS}

This present work is supported by CIHEAM MAIB distance learning and Alumni networking experience, which highlights the need for greater choice in how peer students learn, interact, concerns around course players (Tutors, Instructors, Experts. etc) and the appropriateness of technology used across courses. Overall, recent distance learning courses in combination with Alumni networking and follow-up research study support the creation of a community of practice and peer learning environment where the distinction between teacher and student is increasingly fluid. It is emphasizing also the role of Alumni Network to enable collaboration and the co-production of knowledge. The multi-faceted nature of the institution remains highly valued, as does the multifarious role of the instructors/teachers. However, due to changes in the production and consumption of information in society, the student's role is being reasserted in a new form of peer collaboration; one which we might call the 'student as producer'.

In addition to Alumni initiative and its on-going follow-up survey are still providing a wealth of extremely valuable and reliable indicators, information, ideas and insights for the CIHEAM-MAI of Bari administration. The findings of this study highlight the importance of involving former students/trainees in MAIB's courses and programs curricula. It is also a valuable strategy for providing informative data for the institution which can be utilized in improving various aspects of the current and future education/training programs.

Finally, a limitations of this study is the inability to generalized beyond the study population. All recommendations from this research specifically addressed the CIHEAM-Mediterranean Agronomic Institute of Bari Education/Training programs and former student community. Continued follow-up studies and online courses should be conducted to track curricula changes and determine if those changes are reflected in former trainees' response.

\section{REFERENCES}

Bull, S. \& McCalla, G. (2002). Modelling Cognitive Style in a Peer Help Network, Instructional Science 30(6), 497-528.

Davies, P. (2000). Computerized peer assessment. Innovations in Education and Training International, 37, pp. 346-55.

Driouech, N. (2012). MAIB Former student: Where are they? Follow-up research findings. 
[http://www.iamb.it/share/integra_files_lib/files/ftn/Research\%20studies_1.pdf Accessed 2014].

Erickson C.E., (1947). A basic text for guidance workers. New York: Prentice-Hall, Inc.

Graham L.D. (2001). Are We Preparing the Society Ready Graduate?. 28th Annual national Agricultural Education Research Conference, December 12-2011-P. 269.

Graham, C. R. (2002). Factors for effective learning groups in face-to-face and virtual environments. Quarterly Review of Distance Education, No. 3, pp. 307-319.

Hopkinson, B. (2002). Interaction in online learning. Available online at: [www.ioe.ac.uk/schools/leid/oet/OET\%20html\%202001\%20essay\%20docs/Hopki nson_B.htm Accessed July 2014].

Lambropoulos N., Faulkner X. and Culwin F. (2012). Supporting social awarness in collaborative eLearning. British Journal of Educational Technology. Vol .43 No 2 2012 295-306. doi:10.1111/j.1467-8535.2011.01184.x.

Lave, Jean; Wenger, Etienne (1991). Situated Learning: Legitimate Peripheral Participation. Cambridge: Cambridge University Press. ISBN 0521423740. http://books.google.ca/books?id=CAVIOrW3vYAC.; first published in 1990 as Institute for Research on Learning report 90-0013.

Lorusso O., Sisto L. and Slimani M. (2011). Effects of the tutor and of the «recovery period» on exchange dynamics in the "Forums" of an eLearning course "Formamente", V. VI, n. 1-2, pp. 249-268.

Loumbeva N., Salokhe G., Kolshus K. and Lucie Lamoureux L. 2009. Agricultural Information and Knowledge Management Papers. [http://ftp.fao.org/docrep/fao/012/ak992e/ak992e00.pdf Accessed 2014].

McLuckie, J., \& Topping, K. J. (2004). Transferable skills for online peer learning. Assessment and Evaluation in Higher Education, 29, 563-584.

Merrill, D. C., Reiser, B. J., Ranney, M., \& Trafton, J. G. (1992). Effective tutoring techniques: A comparison of human tutors and intelligent tutoring systems. Journal of the Learning Sciences, 2, 277-305.

Randavay S., (1990). A follow-up study of the Doctoral program in Agricultural and Extension Education. Journal of Agricultural.Volume 31, number 2, pp. 40-44 DOI: 10.50.31/jae. 1990.02040.

Slavin, R. E. (1990). Co-operative learning: Theory, research and practice. Englewood Cliffs, NJ: Prentice Hall.

Topping, K. J. (1999). Formative assessment of reading comprehension by computer. Reading OnLine. Retrieved November 4, 2004, from http::/www.readingonline.org/critical/topping/.

Topping, K. J. (2001a). Peer assisted learning: A practical guide for teachers. Cambridge, MA: Brookline Books.

Topping, K. J. (2005). Trends in Peer Learning. Educational Psychology. Ed. Taylor \& Francis 2005. Vol. 25, No. 6, December 2005, pp. 631-645.

Wenger, Etienne (2007). 'Communities of practice. A brief introduction'. Communities of practice [http://www.ewenger.com/theory/ Accessed January 14, 2009]. Cambridge, MA: Harvard Business School Press. 